FREITAS; Michele dos Santos. Globalização e emergência do direito global: princípio da sustentabilidade e governança frente à crise ambiental. Revista Eletrônica Direito e Política, Programa de Pós-Graduação Stricto Sensu em Ciência Jurídica da UNIVALI, Itajaí, v.14, n.2, $2^{\circ}$ quadrimestre de 2019. Disponível em: www.univali.br/direitoepolitica - ISSN 1980-7791

\title{
GLOBALIZAÇÃO E EMERGÊNCIA DO DIREITO GLOBAL: PRINCÍPIO DA SUSTENTABILIDADE E GOVERNANÇA FRENTE À CRISE AMBIENTAL
}

\author{
GLOBALIZATION AND EMERGENCY OF GLOBAL LAW: THE PRINCIPLE OF \\ SUSTAINABILITY AND GOVERNANCE ENVIRONMENTAL CRISIS
}

Michele dos Santos Freitas ${ }^{1}$

\begin{abstract}
RESUMO
Nos últimos séculos, a exploração desenfreada dos recursos naturais e o caráter antropocêntrico do pensamento do Homem Moderno, a fim de satisfazer suas próprias necessidades, resultaram em um quadro alarmante em relação ao meio ambiente. Com o agravamento da crise viu-se a necessidade de uma postura que prolongue a vida do Ser Humano na terra. Explica-se a precisão de a sustentabilidade e a proteção ambiental terem caráter global, já que as relações sociais e econômicas se dão em níveis nacionais e internacionais, e a degradação do meio ambiente afeta a todos. Desse modo, o presente artigo tem como problemática central analisar como o Direito global fomenta critérios de governança sustentável que possam contribuir para a sustentabilidade ambiental. Assim, a hipótese a ser apresentada está baseada na relevância do princípio da Sustentabilidade e dos caminhos que devem ser trilhados na governança e no direito, tanto a nível local, quanto global. Assim o artigo traz uma breve análise do Direito Global, globalização e transnacionalismo, sob o viés dos direitos humanos na proteção do meio ambiente global.
\end{abstract}

PALAVRAS-CHAVE: Direito Global; Direito e governança; Meio Ambiente. Sustentabilidade.

\begin{abstract}
In recent centuries, the rampant exploitation of natural resources and the anthropocentric character of Modern Man's thought in order to satisfy his own needs have resulted in an alarming picture of the environment. As the crisis worsened, there was a need for a posture that would prolong the life of the Human Being on earth. The precision of sustainability and environmental protection is explained as global, since social and economic relations take place at international levels, and the degradation of the environment affects everyone. Thus, this article has as central problem to analyze how the global law foments criteria of sustainable governance that can contribute to the environmental sustainability. Thus, the hypothesis to be presented is based on the relevance of the principle of

\footnotetext{
1 Mestranda em Direito pela Faculdade Meridional - IMED. Endereço eletrônico para contato: michesfreitas@hotmail.com
} 
FREITAS; Michele dos Santos. Globalização e emergência do direito global: princípio da sustentabilidade e governança frente à crise ambiental. Revista Eletrônica Direito e Política, Programa de Pós-Graduação Stricto Sensu em Ciência Jurídica da UNIVALI, Itajaí, v.14, n.2, $2^{\circ}$ quadrimestre de 2019. Disponível em: www.univali.br/direitoepolitica - ISSN 1980-7791

Sustainability and the paths that must be traced in governance and law, both locally and globally. Thus the article brings a brief analysis of Global Law, globalization and transnationalism, under the human rights bias in the protection of the global environment.

Keywords: Global Law; Law and governance; Environment; Sustainability.

\section{INTRODUÇÃO}

Constantemente tenta-se adaptar à evolução da vida em sociedade no mundo globalizado em que vivemos, pois se entende que qualquer forma de direito somente se justifica se acompanhar a realidade histórica de cada época.

O artigo apresenta alguns dos problemas que o Direito enfrenta na questão de sustentabilidade, preservação ambiental, bem como crises atualmente existentes sucedidas pelos fluxos globalizatórios. Também objetiva analisar critérios que possam contribuir para a sustentabilidade ambiental através da governança global com base no Princípio da Sustentabilidade.

O texto esclarece que a intensificação da sociedade mundial e o consequente processo de globalização, além de exigirem um alargamento global, implicam em deficiência ou incapacidade do ente soberano estatal para certos temas que escapam aos limites de suas fronteiras.

Assim, em um primeiro momento, o presente artigo discorre sobre os processos de globalização, o Direito Transnacional e a emergência do Direito Global. Imprescindível se faz o estudo e uma melhor compreensão do transnacional/global, face sua condição de produzir efeitos não só locais, mas também nacionais e internacionais

Em seguida, explanar sobre a importância e a interdependência dos direitos humanos e o meio ambiente, uma vez que a ONU (Organização das Nações Unidas) deu abertura ao que se pode chamar de Sistema Global de Direitos Humanos. Bem como elucidar sobre a sustentabilidade como caminho a ser trilhado na tentativa de se viver dignamente dentro de um desenvolvimento justo e sustentável. 
FREITAS; Michele dos Santos. Globalização e emergência do direito global: princípio da sustentabilidade e governança frente à crise ambiental. Revista Eletrônica Direito e Política, Programa de Pós-Graduação Stricto Sensu em Ciência Jurídica da UNIVALI, Itajaí, v.14, n.2, $2^{\circ}$ quadrimestre de 2019. Disponível em: www.univali.br/direitoepolitica - ISSN 1980-7791

Num terceiro momento, descrever sobre a governança para a sustentabilidade. A importância do princípio da sustentabilidade como norteador da na governança ambiental mundial.

Deste modo, o presente artigo tem como problemática central analisar como Direito Global fomenta critérios de governança sustentável ambiental. Assim, a hipótese a ser apresentada está baseada na relevância do princípio da Sustentabilidade e dos caminhos que devem ser trilhados na governança e no direito, tanto a nível local, quanto global.

Portanto, o artigo traz uma breve análise do Direito Global, globalização e transnacionalismo, sob o viés dos direitos humanos na proteção do meio ambiente global. A técnica de pesquisa a ser utilizada é a bibliográfica e o método dedutivo.

\section{GLOBALIZAÇÃO, DIREITO TRANSACIONAL E EMERGÊNCIA DO DIREITO GLOBAL}

O processo de globalização necessita ser compreendido como um caminho sem volta. As mudanças que acentuam o ambiente da atualidade, como as questões ambientais, o terrorismo, a tecnologia, os direitos humanos, entre outras, estão em amplos processos de expansão planetário.

A repetição de acontecimentos de crises econômicas, ambientais, sanitárias, energéticas, bem como novos riscos advindo com a ameaça terrorista acelerou a formação de aglomerados policêntricos para a gestão e regulação destas novas manifestações globais2.

O surgimento de novas matrizes de poder exige um novo direito de contenção dos excessos e projeção de expectativas realizáveis em um futuro próximo ${ }^{3}$.

[...] ]as novas realidades ampliam o alcance do Direito Internacional, inclusive em assuntos que não se prendem às fronteiras estatais, como o meio ambiente, o terrorismo, a regulamentação da exploração espacial, o combate à

\footnotetext{
${ }^{2}$ STAFFEN, Márcio Ricardo. Interfaces do direito global. 2. Ed. Rio de Janeiro: Lumen Juris, 2018. ${ }^{3}$ STAFFEN, Márcio Ricardo. Interfaces do direito global. 2. Ed. Rio de Janeiro: Lumen Juris, 2018
} 
FREITAS; Michele dos Santos. Globalização e emergência do direito global: princípio da sustentabilidade e governança frente à crise ambiental. Revista Eletrônica Direito e Política, Programa de Pós-Graduação Stricto Sensu em Ciência Jurídica da UNIVALI, Itajaí, v.14, n.2, $2^{\circ}$ quadrimestre de 2019. Disponível em: www.univali.br/direitoepolitica - ISSN 1980-7791

criminalidade internacional, a proteção do sistema financeiro internacional, as novas forças tecnológicas, as intervenções humanitárias, os direitos humanos, dentre outros4.

As transformações sociais, econômicas, culturais e jurídicas advindas dos fluxos globalizatórios que se operam na atualidade, originaram rupturas com os padrões até então constituídos e, não mais encontram consonância com o modelo de organização social surgido com a modernidade, necessitando de um novo paradigma global.

[...] a globalização é um fenômeno econômico produzido pelas mudanças tecnológicas e pela expansão dos mercados. Uma transformação material irrecusável que imporia a todos os povos as mesmas políticas econômicas e reformas institucionais. Além disso a globalização seria universal, inclusiva, convergente e promoveria uma redução pacífica e positiva da soberania dos Estados nacionais. ${ }^{5}$

Assim, crescentemente, esses processos globalizatórios criaram um território mundial, uma nova ordem supra e transnacional que permite a crise do Estado e institui instrumentos de governança global ${ }^{6}$.

[...]Até agora, somente os Estados poderiam desempenhar o papel de produtores de normatividade. Hoje, no entanto, e em muitas áreas o Estado tornou-se um ator ao lado de outros, e até mesmo como os outros. A esse número de atores transnacionais,- e isto é sobretudo visível no nível globaldevemos acrescentar o conjunto das organizações não governamentais, onde na primeira fileira encontramos aquelas que defendem o meio ambiente ou promovem a democracia e a proteção dos direitos humanos. Nunca, repetimos, as ONGs foram tão fortes. ${ }^{7}$

O decaimento do Estado nacional ocorre de forma gradual e necessária. A justificativa mais forte é o mundo globalizado em que vivemos, mais precisamente,

4 VIVIANI, Maury Roberto. Constitucionalismo Global: Crítica em face da realidade das relações internacionais no cenário de uma nova ordem mundial. Rio de Janeiro: Lumen Juris, 2014.

5 FIORI, José Luís. $\mathbf{O}$ poder global e a nova geopolítica das nações. São Paulo: Boitempo Editorial, 2007.

${ }^{6}$ STAFFEN, Márcio Ricardo. Interfaces do direito global. 2. Ed. Rio de Janeiro: Lumen Juris, 2018.

7 ARNAUD, André-Jean. Governar sem Fronteiras.: entre a globalização e pós globalização. Crítica da Razão Jurídica, vol. 2. Rio de Janeiro: Editora Lumen Juris, 2007. 
FREITAS; Michele dos Santos. Globalização e emergência do direito global: princípio da sustentabilidade e governança frente à crise ambiental. Revista Eletrônica Direito e Política, Programa de Pós-Graduação Stricto Sensu em Ciência Jurídica da UNIVALI, Itajaí, v.14, n.2, $2^{\circ}$ quadrimestre de 2019. Disponível em: www.univali.br/direitoepolitica - ISSN 1980-7791

os problemas naturais mundiais que enfrentamos, fortalecendo assim o movimento das ONGs.

A partir da fragilidade dos tradicionais atores nacionais, espaços de debilidade passa(ra)m a ser ocupados, notadamente após a Segunda Guerra, por interesses transnacionais constituídos através de instituições novas, de difícil caracterização à luz do glossário político-jurídico Moderno ${ }^{8}$.

Não consegue frear os fluxos da globalização no que tange à distribuição do poder ${ }^{9}$, cultura, economia, desigualdade e formas de governo, razão pela qual, há sim, necessidade de um Direito Global (cosmopolita, na adjetivação dos autores) ${ }^{10}$.

[...] Logo, o Direito Global, por mais incipiente que seja, tem como objeto a compreensão e a regulação das relações provenientes dos fluxos globalizatórios. Fluxos estes que não se restringem à globalização do segundo pós-guerra. Contudo, ainda que algumas bases de governar o mundo estejam sedimentadas na descoberta da América, a grande especificidade verte da policentricidade que governa a globalização do terceiro milênio ${ }^{11}$.

Partindo dessa análise em que o Direito deve ter um novo paradigma global, fica claro que mais uma vez é preciso repolitizá-lo, adequando-se às novas realidades.

Para STAFFEN, a aplicação do Direito, em seu conceito, deve ser o "global rule of law", conforme citação abaixo.

A diversidade de conflitos jurídicos e a variedade de sistemas de resolução de disputas no âmbito transnacional nos conduzem indefectivelmente para um conceito mais geral de aplicação do Direito como garantidor das liberdades e da ordem social. Este conceito deve ser, na minha opinião, o da supremacia do Direito Global ou "global rule of law"12.

As mudanças do Direito no contexto da globalização, e consequentemente, dos efeitos da mobilização transnacional do direito implicam a emergência do Direito

\footnotetext{
8 STAFFEN, Márcio Ricardo. Interfaces do direito global. 2. Ed. Rio de Janeiro: Lumen Juris,2018.

9 CALETTI, Leandro; STAFFEN, Márcio Ricardo. A fragmentação jurídica e o direito ambiental global. Veredas do Direito: Direito Ambiental e Desenvolvimento Sustentável, Belo Horizonte, v. 16, n. 34, p. 279-310, mai. 2019.

10 STAFFEN, Márcio Ricardo. Interfaces do direito global. 2. Ed. Rio de Janeiro: Lumen Juris,2018.

11 STAFFEN, Márcio Ricardo. Globalismo Jurídico. Lima. Egacal, 2015.

12 STAFFEN, Márcio Ricardo. Interfaces do direito global. 2. Ed. Rio de Janeiro: Lumen Juris, 2018
} 
FREITAS; Michele dos Santos. Globalização e emergência do direito global: princípio da sustentabilidade e governança frente à crise ambiental. Revista Eletrônica Direito e Política, Programa de Pós-Graduação Stricto Sensu em Ciência Jurídica da UNIVALI, Itajaí, v.14, n.2, $2^{\circ}$ quadrimestre de 2019. Disponível em: www.univali.br/direitoepolitica - ISSN 1980-7791

Global, sustentando uma proteção em escalas local, nacional, regional, internacional.

A principal consequência jurídica que tem a conversão da humanidade em uma comunidade política é a necessidade de estabelecer um ordenamento jurídico global que regule e a organize naquelas matérias que tocam todos os seres humanos ${ }^{13}$.

Como tentativa de organizar um Direito que corresponda a nova atualidade, o pluralismo jurídico, surge como possível solução, onde se cruzam ordens jurídicas nacionais e internacionais.

Nesse sentido Maury Roberto Viviani explicita a importância da idéia de uma ordem internacional constitucionalizada que possa resolver alguns problemas dentro do contexto atual, como o problema da soberania e do papel dos Estados no mundo contemporâneo, o crescimento do número de atores não estatais na esfera pública internacional, a necessidade de cooperação transnacional e os desafios de alguns valores pretendidos como universais. ${ }^{14}$

Assim, o Direito global deve fazer frente a problemas diversos, tais como conflitos de uniformidade e diferenças nacionais, a concorrência de normas globais-nacionais-locais, a atribuição de competências, a regulação do capital e nortes para governança global, a promoção dos Direitos Humanos, a preservação ambiental e critérios de sustentabilidade planetária, o combate de redes criminosas, enfim, uma nova e eficaz forma de limitação de um poder de extrema fluidez, como é a ordem global atual. ${ }^{15}$

Os direitos humanos, por exemplo, expressam nitidamente a necessidade desse mundo globalizado do século XXI. Não adianta garantir o direito à vida, ao bemestar físico, e a dignidade da pessoa humana, se o Planeta está praticamente devastado, e não possui mais condições de garantir a vida.

Os indivíduos, de um modo geral, apoiam-se da premissa de que só é possível existir e satisfazer suas necessidades a partir da exploração infinita - embora não

\footnotetext{
13 STAFFEN, Márcio Ricardo. Interfaces do direito global. 2. Ed. Rio de Janeiro: Lumen Juris, 2018.

14 VIVIANI, Maury Roberto. Constitucionalismo Global: Crítica em face da realidade das relações no cenário de uma nova ordem mundial. Rio de Janeiro: Lúmen Juris, 2014.

15 STAFFEN, Márcio Ricardo. Interfaces do direito global. 2. Ed. Rio de Janeiro: Lumen Juris, 2018.
} 
FREITAS; Michele dos Santos. Globalização e emergência do direito global: princípio da sustentabilidade e governança frente à crise ambiental. Revista Eletrônica Direito e Política, Programa de Pós-Graduação Stricto Sensu em Ciência Jurídica da UNIVALI, Itajaí, v.14, n.2, $2^{\circ}$ quadrimestre de 2019. Disponível em: www.univali.br/direitoepolitica - ISSN 1980-7791

existente - da Natureza e seus recursos naturais. E, o pensamento que paira sobre os indivíduos sobre a finitude dos recursos naturais faz com que, dia a dia, a Natureza seja atropelada pelas invenções humanas e pela tecnologia, cada vez mais à frente do seu tempo.

Nos últimos séculos, a exploração desenfreada dos recursos naturais e o caráter antropocêntrico do pensamento do Homem Moderno, a fim de satisfazer suas próprias necessidades, resultaram em um quadro alarmante. O preço pago pelo desenvolvimento sem limites da Humanidade é a situação lamentável enfrentada nos dias de hoje. Inegável afirmar que o progresso ocorrido através dos tempos, com o surgimento de novas tecnologias, de técnicas industriais, de avanços na comunicação, etc., melhorou a vida dos Homens. Porém as preocupações com o meio ambiente só aumentaram nas últimas décadas e o debate ganhou força em todo o mundo ${ }^{16}$.

O Meio Ambiente e a Mãe-Terra foram abafados pelo antropocentrismo, segundo

o qual os indivíduos passaram a habitar o centro do universo, tornando-se, na visão humana, superiores e suficientes em relação a Natureza.

Os resíduos tóxicos produzidos por fábricas e pelas famílias, estão se acumulando e envenenando o ar, água e solo. Agrotóxicos utilizados na agricultura contaminam os lençóis freáticos que muitos de nos bebemos, e alguns dos nossos alimentos que são o nosso sustento. Nós poluímos os mares, lagos, rios e outras correntes, praticamente em todos os lugares, sobrecarregando-os com substâncias químicas e a introdução de produtos químicos sintéticos que os processos naturais não podem degradar ou reciclar. ${ }^{17}$

Pelo uso desmedido e irresponsável dos recursos naturais, desencadeados por uma economia que faz com que o modo de vida indivíduo-natureza se torne incompatível, o Meio Ambiente passa a ser deteriorado e visto como mero objeto de satisfação dos indivíduos.

A irresponsabilidade se torna desmedida para um mundo sustentável quando a Economia reforça modos de vida incompatíveis com o diálogo entre indivíduo-sociedade-

\footnotetext{
${ }^{16}$ AQUINO, Sérgio Ricardo Fernandes de, As andarilhagens da Sustentabilidade no século XXI/

DE BASTIANI, Ana Cristina Bacega. 1a ed. Florianópolis: Empório do Direito, 2015.

17 SAAVEDRA, Jaime Fernando Estenssoro. História do debate ambiental na política mundial 1945-1992: a perspectiva latino-americana. Tradução de Daniel Rubens Censi. Ijuí, (RS): Editora da UNIJUÍ, 2014.
} 
FREITAS; Michele dos Santos. Globalização e emergência do direito global: princípio da sustentabilidade e governança frente à crise ambiental. Revista Eletrônica Direito e Política, Programa de Pós-Graduação Stricto Sensu em Ciência Jurídica da UNIVALI, Itajaí, v.14, n.2, $2^{\circ}$ quadrimestre de 2019. Disponível em: www.univali.br/direitoepolitica - ISSN 1980-7791

espécie e a Terra. A sobrevivência se transforma em regra social e pode ser disseminada como fenômeno "normal", ou seja, a insustentabilidade humana convive com a sustentabilidade ambiental. ${ }^{18}$

Os impactos ambientais atingiram dimensões globais e hoje a Natureza encontrase em colapso, pois a Humanidade está diante de um limite de crescimento, em razão do estilo de vida adotado. O agravamento da crise ocorreu a partir do final do século XIX, onde o meio ambiente tornou-se o centro de debates em todo mundo, diante da necessidade de uma postura que prolongue a vida do Ser Humano na terra ${ }^{19}$.

Com a idéia de crise ambiental quer-se expressar o fenômeno paradoxal que foi o crescimento econômico em si, pelo elevado nível de desenvolvimento e padrão de vida alcançado pela civilização industrial, em que o Primeiro Mundo é o exemplo emblemático, que gerou problemas de caráter ecológico e ambiental de tão grande magnitude que, pela primeira vez na História colocou-se em risco a continuidade da vida humana na Terra, bem como o processo de vida do próprio planeta. A partir deste diagnóstico, em seguida surgiu toda uma linha de pensamento teórico-político que afirma que estamos diante do problema mais importante e mais urgente a ser enfrentado pela humanidade, nesta etapa histórica do seu desenvolvimento. ${ }^{20}$

Diante da necessidade de um novo paradigma frente aos impactos ambientais, a sustentabilidade aparece no cenário mundial, como caminho a ser trilhado na tentativa de se viver dignamente dentro de um desenvolvimento justo e sustentável.

\section{SUSTENTABILIDADE E A INTER-RELAÇÃO DOS DIREITOS HUMANOS E O MEIO AMBIENTE}

\footnotetext{
18 AQUINO, Sérgio Ricardo Fernandes de. Por uma cidadania sul-americana: fundamentos para a sua viabilidade na UNASUL por meio da Ética, Fraternidade, Sustentabilidade e Política Jurídica. Saarbrücken: Novas Edições Acadêmicas, 2014. p.336.

19 AQUINO, Sérgio Ricardo Fernandes de, As andarilhagens da Sustentabilidade no século XXI/

DE BASTIANI, Ana Cristina Bacega. $1^{\text {a }}$ ed. Florianópolis: Empório do Direito, 2015.

20 SAAVEDRA, Jaime Fernando Estenssoro. História do debate ambiental na política mundial 1945-1992: a perspectiva latino-americana. Tradução de Daniel Rubens Censi. Ijuí, (RS): Editora da UNIJUÍ, 2014.
} 
FREITAS; Michele dos Santos. Globalização e emergência do direito global: princípio da sustentabilidade e governança frente à crise ambiental. Revista Eletrônica Direito e Política, Programa de Pós-Graduação Stricto Sensu em Ciência Jurídica da UNIVALI, Itajaí, v.14, n.2, $2^{\circ}$ quadrimestre de 2019. Disponível em: www.univali.br/direitoepolitica - ISSN 1980-7791

Segundo BOSSELMANN a ideia de sustentabilidade é semelhante a ideia de justiça, pois ao mesmo tempo que temos consciência das coisas sustentáveis, temos consciência das coisas justas, porém ambas devem ser analisada com base nos valores e princípios ${ }^{21}$.

A sustentabilidade como novo paradigma de vida do século XXI, denota primeiramente, quais atitudes devem ser adotadas de modo a enfatizar nossas responsabilidades comuns em prol de um universo inteiro. Antes de tudo pode-se entender como uma forma de filosofia de vida, mas à medida em que é inserida num contexto jurídico, torna-se não somente uma reivindicação de cunho social, mas também reivindica uma Justiça ecológica.

A sustentabilidade, portanto, é associada a ideia de aperfeiçoamento humano, de se criar novas perspectivas que forjem novos vínculos de Responsabilidade e Fraternidade, que traga novos critérios civilizacionais continentais e planetários. De forma sintética: a categoria em estudo sempre é pensada junto à outra chamada Desenvolvimento 22 .

Conforme BOSSELMANN, o conceito de desenvolvimento sustentável apenas é significativo quando relacionado com a ideia central de sustentabilidade ecológica, e que o primeiro deve ser entendido como a aplicação do princípio da Sustentabilidade ${ }^{23}$.

O desafio do Desenvolvimento Sustentável é apresentar novos processos econômicos, novos acessos a direitos os quais se ampliam por meio das diferenças culturais num cenário plurinacional, bens e serviços com a menor perda energética possível. ${ }^{24}$

Nesse diapasão que os direitos humanos e o meio ambiente se relacionam. A ONU (Organização das Nações Unidas) deu abertura ao que se pode chamar de Sistema

21 BOSSELMANN, Klaus. O princípio da sustentabilidade: transformando direito e governança. Tradução de Phillip Gil França. São Paulo: Revista dos Tribunais, 2015

22 AQUINO, Sérgio Ricardo Fernandes de. Por uma cidadania sul-americana: fundamentos para a sua viabilidade na UNASUL por meio da Ética, Fraternidade, Sustentabilidade e Política Jurídica. Saarbrücken: Novas Edições Acadêmicas, 2014. p.336.

23 BOSSELMANN, Klaus. O princípio da sustentabilidade: transformando direito e governança. Tradução de Phillip Gil França. São Paulo: Revista dos Tribunais, 2015

${ }^{24}$ AQUINO, Sérgio Ricardo Fernandes de. Por uma cidadania sul-americana: fundamentos para a sua viabilidade na UNASUL por meio da Ética, Fraternidade, Sustentabilidade e Política Jurídica. 
FREITAS; Michele dos Santos. Globalização e emergência do direito global: princípio da sustentabilidade e governança frente à crise ambiental. Revista Eletrônica Direito e Política, Programa de Pós-Graduação Stricto Sensu em Ciência Jurídica da UNIVALI, Itajaí, v.14, n.2, $2^{\circ}$ quadrimestre de 2019. Disponível em: www.univali.br/direitoepolitica - ISSN 1980-7791

Global de Direitos Humanos, afirmando universalmente a importância dos direitos humanos como base e alicerce para exigir primeiramente a dignidade com o fim de alcançar o progresso social e melhores condições de vida.

Assim é que, conforme a Carta das Nações Unidas, pela primeira vez na história, afirmou-se universalmente a fé nos direitos humanos fundamentais, na dignidade, no valor da pessoa humana, na igualdade de direitos entre nações pequenas e grandes, bem como no estabelecimento de condições, sob as quais a justiça e o respeito às obrigações decorrentes de Tratados e de outras de fontes do direito internacional possam ser mantidos. Além disso, salientou a determinação à promoção do progresso social e de melhores condições de vida em uma liberdade mais ampla. O comprometimento demonstrado no preâmbulo da Carta de 1945 era para com todos os povos, todas as culturas e todas as pessoas, de maneira global. ${ }^{25}$

A efetividade dos Direitos Humanos enquanto garantidor da dignidade humana depende da prática de vários movimentos sociais interligados, tanto na sua utilização cerimonial quanto na sua mobilização processual. Nesse sentido, a proteção da vida e da dignidade humana e a proteção do meio ambiente seguem a mesma preocupação básica com a vida.

[...] Por um lado, os direitos humanos têm também uma utilização formal, enquanto instrumento jurídico de proteção, reparação e mobilização. Por outro lado, surgem como ferramenta discursiva, visando dotar de maior abrangência e legitimidade causas que, de contrário estariam mais vulneráveis ao silenciamento e à invisibilidade, por serem historicamente alvo de processos de opressão. Em qualquer dos casos, trata-se de uma apropriação estratégica, apoiada numa ideologia que se acredita partilhada pela generalidade da população ${ }^{26}$.

O meio ambiente é uma das grandes preocupações dentro dos direitos humanos, pois a existência da crise ambiental global afeta a todos, em escala planetária. É através dos direitos humanos que ocorrem as primeiras tentativas de proteção ambiental como uma questão de necessidade básica.

\footnotetext{
25 GRUBBA, Leilane Serratine. Direitos Humanos e Desenvolvimento Humano: O Sistema Global Das Nações Unidas. Curitiba: editora Prismas, 2017.

26 SANTOS, Cecília MacDowell dos. A mobilização transnacional do direito. Portugal e os Tribunal Europeu dos Direitos Humanos. Coimbra: Almedina, 2012
} 
FREITAS; Michele dos Santos. Globalização e emergência do direito global: princípio da sustentabilidade e governança frente à crise ambiental. Revista Eletrônica Direito e Política, Programa de Pós-Graduação Stricto Sensu em Ciência Jurídica da UNIVALI, Itajaí, v.14, n.2, $2^{\circ}$ quadrimestre de 2019. Disponível em: www.univali.br/direitoepolitica - ISSN 1980-7791

Segundo BOSSELMANN 27 a interdependência entre direitos humanos e proteção ambiental tem sido crescentemente reconhecida no direito internacional e nacional. Destarte, os direitos humanos tornam-se uma arma poderosíssima voltado para o confronto das contradições existentes nas mais diversas áreas sociais, culturais, ambientais, econômicas e jurídicas.

O regime internacional para a proteção dos direitos humanos se desenvolveu de modo diferente da proteção do meio ambiente. O primeiro surgiu do reconhecimento das liberdades fundamentais após a $2^{a}$ Guerra Mundial, particularmente com a Declaração Universal dos Direitos Humanos de 1948. A segunda surgiu do reconhecimento da existência de uma crise ambiental global, particularmente com a Conferencia sobre o Meio Ambiente Humano realizada em Estocolmo em 1972. ${ }^{28}$

Nesse sentido, a realização da Conferência da ONU em Estocolmo em 1972 foi um passo muito importante no enfrentamento do problema da crise ambiental. O tema surgiu politicamente após o fim da Segunda Guerra Mundial, destaca os períodos do surgimento e a instalação do tema ambiental na política mundial nos períodos de 1945 a 1992.

Considera-se geralmente que o grande marco que colocou este problema na agenda pública mundial é realizada, pela Organização Nações Unidas (ONU), da $1^{\text {a }}$ Conferência sobre o Meio Ambiente Humano, realizada em Estocolmo em 1972. Naquela ocasião afirmou-se formalmente que o mundo estava enfrentando uma crise ambiental global e que a partir desse momento ações conjuntas seriam iniciadas para superar este problema, criando, entre outras medidas, o Programa das Nações Unidas para o Meio Ambiente. ${ }^{29}$

27 BOSSELMANN, Klaus. O princípio da sustentabilidade: transformando direito e governança. Tradução de Phillip Gil França. São Paulo: Revista dos Tribunais, 2015.

28 BOSSELMANN, Klaus. O princípio da sustentabilidade: transformando direito e governança. Tradução de Phillip Gil França. São Paulo: Revista dos Tribunais, 2015.

${ }^{29}$ SAAVEDRA, Jaime Fernando Estenssoro. História do debate ambiental na política mundial 1945-1992: a perspectiva latino-americana. Tradução de Daniel Rubens Censi. Ijuí, (RS): Editora da UNIJUÍ, 2014. 
FREITAS; Michele dos Santos. Globalização e emergência do direito global: princípio da sustentabilidade e governança frente à crise ambiental. Revista Eletrônica Direito e Política, Programa de Pós-Graduação Stricto Sensu em Ciência Jurídica da UNIVALI, Itajaí, v.14, n.2, 20 quadrimestre de 2019. Disponível em: www.univali.br/direitoepolitica - ISSN 1980-7791

A importância abrangente da sustentabilidade exige uma abordagem mais coerente, fundamentalmente um regime globalizante e unificador dos direitos e obrigações humanos[... $]^{30}$

O meio ambiente, como direito humano e fundamental previsto em Constituição já é uma realidade nos dias atuais. Há disposições constitucionais neste sentido em diversos países, inclusive no Brasil. As ações com o condão de conservar, preservar e proteger o direito humano e fundamental ao meio ambiente revela a preocupação da Humanidade diante do atual panorama instaurado: a degradação da natureza (fomentada pelo capitalismo, globalização, consumismo exacerbado, entre outros) e a finitude dos recursos naturais essenciais ${ }^{31}$.

Portanto, a crise ambiental, ocasionada por diferentes fatores, entre eles, o capitalismo irracional, o desenvolvimento industrial, o consumismo desenfreado, o aumento da população, a finitude dos recursos naturais, entre outros, fez com que o mundo se voltasse para a Sustentabilidade.

Na sua forma mais elementar, a sustentabilidade reflete a pura necessidade. O ar que respiramos, a água que bebemos, os solos que fornecem o nosso alimento são essenciais para nossa sobrevivência. A regra básica da existência humana é manter a sustentabilidade das condições de vida de que depende. $[. .]^{32}$

Finalmente, a diversidade de conflitos jurídicos e a variedade de sistemas de resolução de disputas no âmbito transnacional nos conduzem em direção à um Direito Global. Inserindo assim, a governança da sustentabilidade ambiental em benefício das gerações atuais e futuras.

\section{CRISE AMBIENTAL, PRINCÍPIO DA SUSTENTABILIDADE: DIREITO E GOVERNANÇA}

\footnotetext{
30 BOSSELMANN, Klaus. O princípio da sustentabilidade: transformando direito e governança. Tradução de Phillip Gil França. São Paulo: Revista dos Tribunais, 2015.

31 AQUINO, Sérgio Ricardo Fernandes de, As andarilhagens da Sustentabilidade no século XXI/

DE BASTIANI, Ana Cristina Bacega. $1^{a}$ ed. Florianópolis: Empório do Direito, 2015

32 BOSSELMANN, Klaus. O princípio da sustentabilidade: transformando direito e governança. Tradução de Phillip Gil França. São Paulo: Revista dos Tribunais, 2015
} 
FREITAS; Michele dos Santos. Globalização e emergência do direito global: princípio da sustentabilidade e governança frente à crise ambiental. Revista Eletrônica Direito e Política, Programa de Pós-Graduação Stricto Sensu em Ciência Jurídica da UNIVALI, Itajaí, v.14, n.2, $2^{\circ}$ quadrimestre de 2019. Disponível em: www.univali.br/direitoepolitica - ISSN 1980-7791

O desejo de um desenvolvimento sustentável é realizado através da sustentabilidade na medida em que esta incorpora função normativa com base no Princípio da Sustentabilidade. Portanto, o princípio da Sustentabilidade é o norte dos caminhos que devem ser trilhados na governança e no direito, tanto a nível local, quanto global.

[...]se hoje o conceito de desenvolvimento sustentável é reconhecido como um princípio de direito internacional, ele deve sua razão principal, ou seja, qualidade operacional, ao princípio da sustentabilidade. Sem ele, o desenvolvimento sustentável (o que exige a integração dos objetivos ambientais, sociais e econômicos) não poderia para funcionar. Isso é fundamental para reconhece-lo como uma norma jurídica. Em outras palavras, o conceito de desenvolvimento sustentável só pode desempenhar as suas funções normativas na medida em que incorpora a ideia de sustentabilidade ecológica. ${ }^{33}$

Sob essa ótica, a justa aplicação do princípio da Sustentabilidade deve ocorrer imediatamente, evitando-se que se mantenha essa noção tão somente como uma utopia. O ser humano precisa aprender a viver dentro dos limites impostos pela Natureza, não apenas para preservá-la, como também, e, principalmente, para garantir a continuidade da vida na Terra.

Reconhece assim, a Sustentabilidade como um princípio geral da lei, que deve ser adotado por todas as nações, numa compreensão que é cada vez mais imprescindível. Os governos devem desenvolver a governança voltada a Sustentabilidade, criando leis e políticas públicas que implementem e desenvolvam-se.

[...] os tratados, leis e princípios jurídicos existentes devem ser interpretados à luz do princípio da sustentabilidade. Ele fornece orientações fundamentais para a interpretação das normas jurídicas e estabelece a referência para a compreensão da justiça, direitos humanos e soberania do Estado. Ao fazer isso, a sustentabilidade representa o conceito fundamental de emergentes "direitos sustentáveis", baseados na justiça ecológica, direitos humanos e instituições. ${ }^{34}$

33 BOSSELMANN, Klaus. O princípio da sustentabilidade: transformando direito e governança. Tradução de Phillip Gil França. São Paulo: Revista dos Tribunais, 2015

34 BOSSELMANN, Klaus. O princípio da sustentabilidade: transformando direito e governança. Tradução de Phillip Gil França. São Paulo: Revista dos Tribunais, 2015 
FREITAS; Michele dos Santos. Globalização e emergência do direito global: princípio da sustentabilidade e governança frente à crise ambiental. Revista Eletrônica Direito e Política, Programa de Pós-Graduação Stricto Sensu em Ciência Jurídica da UNIVALI, Itajaí, v.14, n.2, $2^{\circ}$ quadrimestre de 2019. Disponível em: www.univali.br/direitoepolitica - ISSN 1980-7791

Se aceitarmos, portanto, que a integridade dos ecossistema da Terra não pode ser fatiada em pedaços que se encaixam em áreas dentro ou fora das fronteiras nacionais, então os estudos precisam estar vinculados a um princípio universal."35

Nesse contexto, surge no âmbito do direito internacional, algumas leis e tratados que buscam a proteção e o respeito ao meio ambiente, com o intuito de equilibrar as questões ambientais, econômicas, sociais e comerciais. Contudo, conforme se analisa pelo atual cenário global, essa busca e pretendida efetividade acontece gradualmente em decorrência de seu tempo de maturação dentro da sustentabilidade, bem como, por vezes a integridade ecológica é deixada de lado, em detrimento da busca da soberania territorial e de outras emergências sociais.

Enquanto os Estados tiverem o monopólio para determinar o papel das instituições internacionais, eles seguirão suas necessidades e não as necessidades de governança ecológica. Como os Estados são favoráveis a objetivos econômicos de curto prazo e não metas ambientais de longo prazo, eles "não necessariamente escolhem as ferramentas mais efetivas para o encontro das metas políticas, ao contrário, vão escolher as ferramentas mais benéficas para eles, politicamente. ${ }^{36}$

Portanto, há necessidade de uma cooperação em prol do meio ambiente. Com a adoção posterior dos Pactos Internacionais dos Direitos Econômicos, Sociais e Culturais e dos Direitos Civis e Políticos, em 1966, os Estados reconheceram a existência de restrições à sua governança interna. ${ }^{37}$

A justificativa mais forte para a cidadania global é o mundo globalizado em que vivemos, mais precisamente, os problemas naturais mundiais que enfrentamos. Nada disso pode ser resolvida por Estados e seus cidadãos apenas (ou sozinhos). Estados, e cidadãos, são praticamente forçados para dentro da eco(lógica) da cidadania global. Ao menos, a cidadania tradicional precisa transformar-se em um novo modelo de cidadania em camadas. ${ }^{38}$

35 BOSSELMANN, Klaus. O princípio da sustentabilidade: transformando governança. Tradução de Phillip Gil França. São Paulo: Revista dos Tribunais, 2015.

36 BOSSELMANN, Klaus. O princípio da sustentabilidade: transformando governança. Tradução de Phillip Gil França. São Paulo: Revista dos Tribunais, 2015.

37 BOSSELMANN, Klaus. O princípio da sustentabilidade: transformando direito e governança. Tradução de Phillip Gil França. São Paulo: Revista dos Tribunais, 2015.

38 BOSSELMANN, Klaus. O princípio da sustentabilidade: transformando direito e governança. Tradução de Phillip Gil França. São Paulo: Revista dos Tribunais, 2015. 
FREITAS; Michele dos Santos. Globalização e emergência do direito global: princípio da sustentabilidade e governança frente à crise ambiental. Revista Eletrônica Direito e Política, Programa de Pós-Graduação Stricto Sensu em Ciência Jurídica da UNIVALI, Itajaí, v.14, n.2, $2^{\circ}$ quadrimestre de 2019. Disponível em: www.univali.br/direitoepolitica - ISSN 1980-7791

Os acontecimentos transcendem as fronteiras dos países, e os fenômenos não ocorrem mais isoladamente, mas globalmente. Esta preocupação a nível global e que enseja associação das nações ocorre porque todos compartilham de um lar comum. Conforme AQUINO ${ }^{39}$ o propósito desse Direito da Sustentabilidade deve ser pensado a partir da espécie humana para se resolver problemas globais.

Em relação as instituições de governança " o Estado é a principal instituição da governança ambiental. Relacionar o princípio da sustentabilidade ao conceito de soberania nos permite incluir funções de tutela do Estado. No mesmo sentido podemos relacionar o princípio da sustentabilidade a outros institutos participantes na governança ambiental mundial. Estes incluem organizações internacionais(OIGs), organizações não governamentais(ONGs) e sociedade civil com a ideia de cidadania em sua essência, Juntamente com os Estados, todos participam da governança ambiental ${ }^{40}$.

Assim, os Estados devem, portanto, incorporar, em seus Ordenamentos Jurídicos, o princípio da Sustentabilidade, que deve ser usado de base para a criação e interpretação de normas ambientais, garantindo a proteção ecológica e o equilíbrio do Planeta, com o fim de uma governança para sustentabilidade em nível global.

Fundamentalmente, precisamos pensar de forma diferente sobre a governança e o papel das pessoas nela. A governança não pode mais ser limitada as relações puramente sociais. Precisamos também refletir as nossas relações ecológicas ${ }^{41}$.

Conforme BOSSELMANN ${ }^{42}$, quando pensamos no papel da governança, devemos refletir as nossas relações ecológicas e não simplesmente as relações sociais. Assim, pensando num todo, a inclusão de toda a vida (além da vida humana) marca uma mudança importante.

${ }^{39}$ AQUINO, Sérgio Ricardo Fernandes de. Por uma cidadania sul-americana: fundamentos para a sua viabilidade na UNASUL por meio da Ética, Fraternidade, Sustentabilidade e Política Jurídica. Saarbrücken: Novas Edições Acadêmicas, 2014. p.336.

40 BOSSELMANN, Klaus. O princípio da sustentabilidade: transformando direito e governança. Tradução de Phillip Gil França. São Paulo: Revista dos Tribunais, 2015

41 BOSSELMANN, Klaus. O princípio da sustentabilidade: transformando direito e governança. Tradução de Phillip Gil França. São Paulo: Revista dos Tribunais, 2015

42 BOSSELMANN, Klaus. O princípio da sustentabilidade: transformando direito e governança. Tradução de Phillip Gil França. São Paulo: Revista dos Tribunais, 2015 
FREITAS; Michele dos Santos. Globalização e emergência do direito global: princípio da sustentabilidade e governança frente à crise ambiental. Revista Eletrônica Direito e Política, Programa de Pós-Graduação Stricto Sensu em Ciência Jurídica da UNIVALI, Itajaí, v.14, n.2, $2^{\circ}$ quadrimestre de 2019. Disponível em: www.univali.br/direitoepolitica - ISSN 1980-7791

Essa mudança nada mais é do que a mudança do antropocentrismo para o ecocentrismo. BOSSELMANN ${ }^{43}$ explicita que esta não deve ser somente conceitual, mas deve ocorrer na prática de forma evolutiva e gradual para que viabilize a sustentabilidade como objetivo.

Nesse sentido, o homem deixa de ser centro do universo e compreende-se a sustentabilidade não só da humanidade, mas da biodiversidade em todos os aspectos, trazendo assim, a ecologia para o centro.

O texto principal da lei do meio ambiente na Nova Zelândia considera a Carta da Terra uma inspiração para o modelo de governança baseado na sustentabilidade. Referindo-se à "importância da ecologia dos não humanos ou de uma biodiversidade ampla" e ao "guardião da terra e princípio da confiança"[...] Tal ligação da Carta da Terra com um sistema nacional legal pode ser típica para os textos de lei do meio ambiente; entretanto, demonstra a sinergia entre ética, lei e governança ${ }^{44}$.

Assim , conforme BOSSELMANN ${ }^{45}$ a sustentabilidade é um princípio ético fundamental com orientação clara para o projeto de lei e governança. Sob essa ótica, a justa aplicação do princípio da Sustentabilidade deve ocorrer imediatamente, evitando-se que se mantenha essa noção tão somente como uma utopia.

A ambição da carta da Terra é "levar adiante a sociedade da sustentabilidade global fundada no respeito à natureza, direitos humanos, universal, justiça econômica, e cultura e paz"(Preâmbulo, primeiro parágrafo). A Carta, por si, organiza 77 princípios em torno de 4 principais temas: "Respeito e cuidado com a Comunidade da Vida" (Princípio 14), "Integridade Ecológica" (5-8), "Justiça Economica e Social" (9-12) e "Democracia, Não violência e Paz" (13-16)

43 BOSSELMANN, Klaus. O princípio da sustentabilidade: transformando governança. Tradução de Phillip Gil França. São Paulo: Revista dos Tribunais, 2015

44 BOSSELMANN, Klaus. O princípio da sustentabilidade: transformando governança. Tradução de Phillip Gil França. São Paulo: Revista dos Tribunais, 2015 45 BOSSELMANN, Klaus. O princípio da sustentabilidade: transformando direito e governança. Tradução de Phillip Gil França. São Paulo: Revista dos Tribunais, 2015

46 BOSSELMANN, Klaus. O princípio da sustentabilidade: transformando governança. Tradução de Phillip Gil França. São Paulo: Revista dos Tribunais, 2015

direito e direito e direito e 
FREITAS; Michele dos Santos. Globalização e emergência do direito global: princípio da sustentabilidade e governança frente à crise ambiental. Revista Eletrônica Direito e Política, Programa de Pós-Graduação Stricto Sensu em Ciência Jurídica da UNIVALI, Itajaí, v.14, n.2, $2^{\circ}$ quadrimestre de 2019. Disponível em: www.univali.br/direitoepolitica - ISSN 1980-7791

Nesse contexto, surge no âmbito do direito internacional, algumas leis e tratados que buscam a proteção e o respeito ao meio ambiente, com o intuito de equilibrar as questões ambientais, econômicas, sociais e comerciais.

Governança é a soma das várias formas individuais e instituições, públicas e privadas, de gerir seus interesses comuns. É um processo contínuo por meio do qual interesses conflitantes ou divergentes podem ser acomodados e ações cooperativas podem ser tomadas ${ }^{47}$.

Contudo, a integridade ecológica é deixada de lado em detrimento da busca pela soberania territorial e outras emergências de cunho econômico, porém, conforme se analisa pelo atual cenário global, essa busca e pretendida efetividade acontece gradualmente em decorrência de seu tempo de maturação dentro da sustentabilidade.

Portanto a governança da sustentabilidade é uma possível solução em despeito à crise ambiental, se compreendida com base nas relações ecológicas, a partir do seu princípio ético e norteador das relações que sustentam o desenvolvimento sustentável com a preocupação das gerações atuais e futuras.

Nesse contexto, a ação cooperativa das Organizações não governamentais (ONGs), Organizações Internacionais (OIGs), a sociedade civil e os Estados, estão inteiramente ligados através das mobilizações transnacionais do direito em prol do meio ambiente.

\section{CONSIDERAÇÕES FINAIS}

A medida que o mundo torna-se cada vez mais interdependente e frágil, o futuro enfrenta, ao mesmo tempo, grandes perigos e grandes promessas. Para seguir adiante, deve-se reconhecer que no meio de uma magnífica diversidade de culturas e formas de vida, somos uma família humana e uma comunidade terrestre com um destino comum.

47 BOSSELMANN, Klaus. O princípio da sustentabilidade: transformando direito e governança. Tradução de Phillip Gil França. São Paulo: Revista dos Tribunais, 2015 
FREITAS; Michele dos Santos. Globalização e emergência do direito global: princípio da sustentabilidade e governança frente à crise ambiental. Revista Eletrônica Direito e Política, Programa de Pós-Graduação Stricto Sensu em Ciência Jurídica da UNIVALI, Itajaí, v.14, n.2, $2^{\circ}$ quadrimestre de 2019. Disponível em: www.univali.br/direitoepolitica - ISSN 1980-7791

Deve-se somar forças para gerar uma sociedade sustentável global baseada no respeito pela natureza, nos direitos humanos universais, na justiça econômica e numa cultura da paz. Para chegar a este propósito, é imperativo que, nós, os povos da Terra, declaremos nossa responsabilidade uns para com os outros, com a grande comunidade da vida, e com as futuras gerações.

Reconhece assim, a Sustentabilidade como um princípio geral da lei, que deve ser adotado por todas as nações, numa compreensão que é cada vez mais imprescindível. Os governos devem desenvolver a governança voltada a Sustentabilidade, criando leis e políticas públicas que implementem e desenvolvam-se.

A conscientização, acerca do respeito aos bens naturais é um processo que demanda tempo, na medida em que é necessário promover uma mudança de valores nas pessoas e nas sociedades. Imprescindível, portanto, que o direito tome as rédeas da situação, e promova leis que "incentivem" o respeito e proteção da natureza.

Os países devem, portanto, incorporar, em seus Ordenamentos Jurídicos, o princípio da Sustentabilidade, que deve ser usado de base para a criação e interpretação de normas ambientais, garantindo a proteção ecológica e o equilíbrio do Planeta.

Algumas nações já incorporaram legislações pautadas no princípio Sustentabilidade, mais especificamente no Desenvolvimento Sustentável, contudo elas representam uma minoria, embora haja um grande empenho por parte de alguns juristas e algumas pessoas em promover a conscientização da relação harmônica entre o homem/natureza.

Quando se tem um conflito entre o respeito a natureza e o pretenso desenvolvimento econômico, a decisão é evidente, a natureza deve ser protegida, pois é somente com a sua proteção que se preserva o equilíbrio natural, e, a vida, porém nem sempre é o que acontece.

A efetiva implementação da sustentabilidade depende dos direitos e deveres das pessoas que precisam assumir a responsabilidade por seus atos, e, tomar 
FREITAS; Michele dos Santos. Globalização e emergência do direito global: princípio da sustentabilidade e governança frente à crise ambiental. Revista Eletrônica Direito e Política, Programa de Pós-Graduação Stricto Sensu em Ciência Jurídica da UNIVALI, Itajaí, v.14, n.2, $2^{\circ}$ quadrimestre de 2019. Disponível em: www.univali.br/direitoepolitica - ISSN 1980-7791

consciência da importância da preservação ambiental, não só pela crise atual, mas pensando igualmente nas gerações futuras.

Os limites de um país não são respeitados pelo meio ambiente, e por isso, a governança desses deve se dar em nível internacional, e vinculadas ao princípio da Sustentabilidade. O ecossistema terrestre, formado por vários sistemas ecológicos que se encontram interligados, requerem que a lei seja implementada em todos esses países, para que a preservação dela ocorra efetivamente. Assim, alcançar novos paradigmas globais, que atendam as novas matrizes do contexto atual, em âmbito social econômico e, sobretudo, ambiental.

\section{REFERÊNCIA DAS FONTES CITADAS}

AQUINO, Sérgio Ricardo Fernandes de. Por uma cidadania sul-americana: fundamentos para a sua viabilidade na UNASUL por meio da Ética, Fraternidade, Sustentabilidade e Política Jurídica. Saarbrücken: Novas Edições Acadêmicas, 2014.

AQUINO, Sérgio Ricardo Fernandes de, As andarilhagens da Sustentabilidade no século XXI/DE BASTIANI, Ana Cristina Bacega. $1^{\text {a }}$ ed. Florianópolis: Empório do Direito, 2015.

ARNAUD, André-Jean. Governar sem Fronteiras.: entre a globalização e pós globalização. Crítica da Razão Jurídica, vol. 2. Rio de Janeiro: Editora Lumen Juris, 2007.

BOSSELMANN, Klaus. O princípio da sustentabilidade: transformando direito e governança. Tradução de Phillip Gil França. São Paulo: Revista dos Tribunais, 2015.

CALETTI, Leandro; STAFFEN, Márcio Ricardo. A fragmentação jurídica e o direito ambiental global. Veredas do Direito: Direito Ambiental e Desenvolvimento Sustentável, Belo Horizonte, v. 16, n. 34, p. 279-310, mai. 2019.

FIORI, José Luís. O poder global e a nova geopolítica das nações. São Paulo: Boitempo Editorial, 2007.

GRUBBA, Leilane Serratine. Direitos Humanos e Desenvolvimento Humano: O Sistema Global Das Nações Unidas. Curitiba: editora Prismas, 2017.

SAAVEDRA, Jaime Fernando Estenssoro. História do debate ambiental na política mundial 1945-1992: a perspectiva latino-americana. Tradução de Daniel Rubens Censi. Ijuí, (RS): Editora da UNIJUÍ, 2014. 
FREITAS; Michele dos Santos. Globalização e emergência do direito global: princípio da sustentabilidade e governança frente à crise ambiental. Revista Eletrônica Direito e Política, Programa de Pós-Graduação Stricto Sensu em Ciência Jurídica da UNIVALI, Itajaí, v.14, n.2, $2^{\circ}$ quadrimestre de 2019. Disponível em: www.univali.br/direitoepolitica - ISSN 1980-7791

SANTOS, Cecília MacDowell dos. A mobilização transnacional do direito. Portugal e os Tribunal Europeu dos Direitos Humanos. Coimbra: Almedina, 2012.

SEN, Amartya Kumar. Desenvolvimento como liberdade. São Paulo: Companhia das Letras, 2010.

STAFFEN, Márcio Ricardo. Interfaces do direito global. 2. Ed. Rio de Janeiro: Lumen Juris, 2018.

STAFFEN, Márcio Ricardo. Globalismo Jurídico. Lima: EGACAL, 2015.

VIVIANI, Maury Roberto. Constitucionalismo Global: Crítica em face da realidade das relações internacionais no cenário de uma nova ordem mundial. Rio de Janeiro: Lumen Juris, 2014.

RECEBIDO EM: 03/05/2019

APROVADO EM: 04/07/2019 